\title{
HMB-45 negative angiomyolipoma of the orbit: a case report and review of the literature
}

\author{
Che-Yu Lin ${ }^{1,2}$, Chieh-Chih Tsai ${ }^{1,2^{*}}$, Hui-Chuan Kau ${ }^{2,3}$, Wei-Kuang Yu ${ }^{1,2}$, Shu-Ching Kao ${ }^{1,2}$ \\ and Catherine Jui-Ling Liu ${ }^{1,2}$
}

\begin{abstract}
Background: Angiomyolipoma is a benign mesenchymal tumor composed of variable amounts of smooth muscle, adipose tissue and thick-walled blood vessels, and usually named PEComas (perivascular epithelioid cell tumors). PEComas share overlapping histopathological features with epithelioid cells along a perivascular distribution and characteristic immunohistochemistry with coexpression of myoid and melanocytic markers (HMB-45 /or Melan-A). We report the first case of primary orbital angiomyolipoma with negative melanocytic marker.
\end{abstract}

Case presentation: An 80-year-old Asian woman had a 2-year history of progressive swelling in the left upper eyelid. External examination revealed $3 \mathrm{~cm}$ of relative proptosis of the left eye and a palpable mass in the left superonasal orbit. Computed tomographic scan demonstrated a circumscribed, heterogeneous orbital mass. Excision biopsy was done and the histological finding demonstrated the orbital mass was composed of mature adipocytes, intermingled with spindle or oval-shaped cells, and accompanied by thick-walled blood vessels. Immunohistochemically, tumor cells were positive for CD34 and HHF-35, but negative for cytokeratin, HMB-45 and Melan-A. The diagnosis of angiomyolipoma was made. No recurrence was noted at 2-year follow-up.

Conclusion: In our case, the HMB-45 negativity may be explained by the rarity of the epithelioid cells, and the HMB-45 positivity is often weaker or absent in spindle cells. Angiomyolipoma, although rare, should be added to the differential diagnosis of space-occupying orbital lesion.

Keywords: Orbit, Angiomyolipoma, Perivascular epithelioid cell tumors, HMB-45

\section{Background}

Angiomyolipoma, originally thought to be a hamartoma, is a benign mesenchymal tumor composed of variable amounts of smooth muscle, adipose tissue and thickwalled blood vessels, and usually named PEComas (perivascular epithelioid cell tumors). It occurs most commonly in the kidney as a sporadic case or as part of the tuberous sclerosis complex [1]. We presented the

\footnotetext{
* Correspondence: cctsai1234@yahoo.com

'Department of Ophthalmology, Taipei Veterans General Hospital, No. 201, Sec.2, Shih-Pai Road, Taipei 11217Taiwan, R.O.C.

${ }^{2}$ Department of Ophthalmology, School of Medicine, National Yang-Ming

University, Taipei, Taiwan

Full list of author information is available at the end of the article
}

first case of primary orbital angiomyolipoma with negative melanocytic markers.

\section{Case presentation}

An 80-year-old woman had a 2-year history of progressive fullness in the left upper eyelid. External examination revealed $3 \mathrm{~mm}$ of relative proptosis of the left eye and a nontender palpable firm mass in the left superonasal orbit (Fig. 1a). The remainder of the ocular examination was within normal limit. Past medical history was otherwise unremarkable. Computed tomographic scan demonstrated a circumscribed, heterogeneous orbital mass displacing the left globe laterally (Fig. 1b, c and d). Surgical removal of the tumor was performed through 

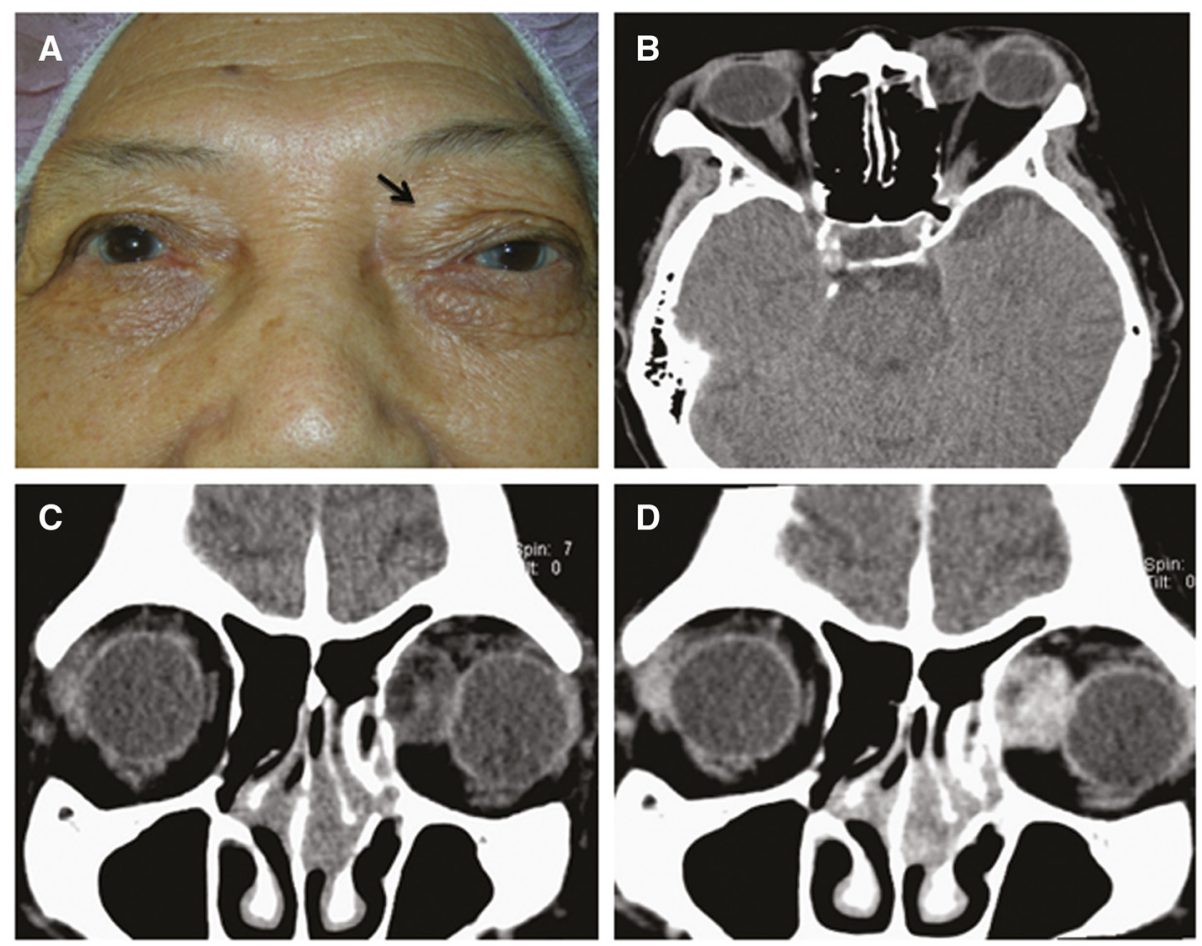

Fig. 1 Preoperative photograph shows a palpable mass on left superonasal orbit (a, arrow). Axial (b) and coronal (c) planes of computed tomographic scan show a circumscribed soft tissue mass on the left superonasal orbit with heterogenic density containing areas of fat attenuation. The mass demonstrates heterogenous enhancement (d)

anterior orbitotomy in an en bloc fashion. At the time of surgery, the $1.8 \times 1.8 \times 1.3 \mathrm{~cm}$ yellowish mass was encapsulated and solid (Fig. 2a). Histologically, the orbital mass was composed of mature adipocytes, intermingled with spindle or oval-shaped cells with eosinophilic cytoplasm, accompanied by thick-walled blood vessels (Fig. 2b). Immunohistochemically, tumor cells were positive for CD34 and HHF-35 (Fig. 2c and d), but negative for cytokeratin, HMB-45 and Melan-A. These findings confirmed the diagnosis of angiomyolipoma. Systemic check-up was unremarkable. No recurrence was noted at 2-year follow-up.

Primary orbital angiomyolipoma is a rare entity of orbital tumor. Until now, only 4 cases of ocular perivascular epithelioid cell tumor (PEComa) have been reported, and all had positive melanocytic markers [2-4]. All reported 4 cases of ocular PEComas were female and their tumor location was eyelid ( 2 cases), ciliary body (1 case), and orbit (1 case) respectively. PEComas often share overlapping histopathological features with epithelioid cells along a perivascular distribution and characteristic immunohistochemistry with coexpression of myoid and melanocytic markers (HMB-45 /or Melan-A) [5]. Current case is unique in that the tumor lacked reactivity for melanin-associated antigens HMB-45 and
Melan-A, which is similar to some angiomyolipomas from skin, head and neck [6-9]. The HMB-45 negativity may be explained by the rarity of the epithelioid cells in these cases, and the HMB- 45 positivity is often weaker or absent in spindle cells [9]. In addition, these angiomyolipomas are usually relative small, contrary to what happens to kidney and liver tumors, which are often large. However, because of the small number of reported cases, whether these HMB-negative angiomyolipoma is a new variant of PEComas require further investigation. Differential diagnosis should include giant cell angiofibroma which is a highly vascular tumor comprising a spindle-cell proliferation with numerous multinucleated giant cells and pseudovascular spaces, and immunohistochemically positive for CD34, CD99, and vimentin [10].

Approximately one third of renal angiomyolipomas occur in patients with tuberous sclerosis. However, this association has been rarely reported in extrarenal angiomyolipoma, including of ocular angiomyolipoma. Because most angiomyolipomas contain varied amounts of adipose tissue, image features of fat attenuation at unenhanced CT may help in diagnosis. Although most angiomyolipomas show a benign course, some reports have suggested that histologically atypical angiomyolipomas 

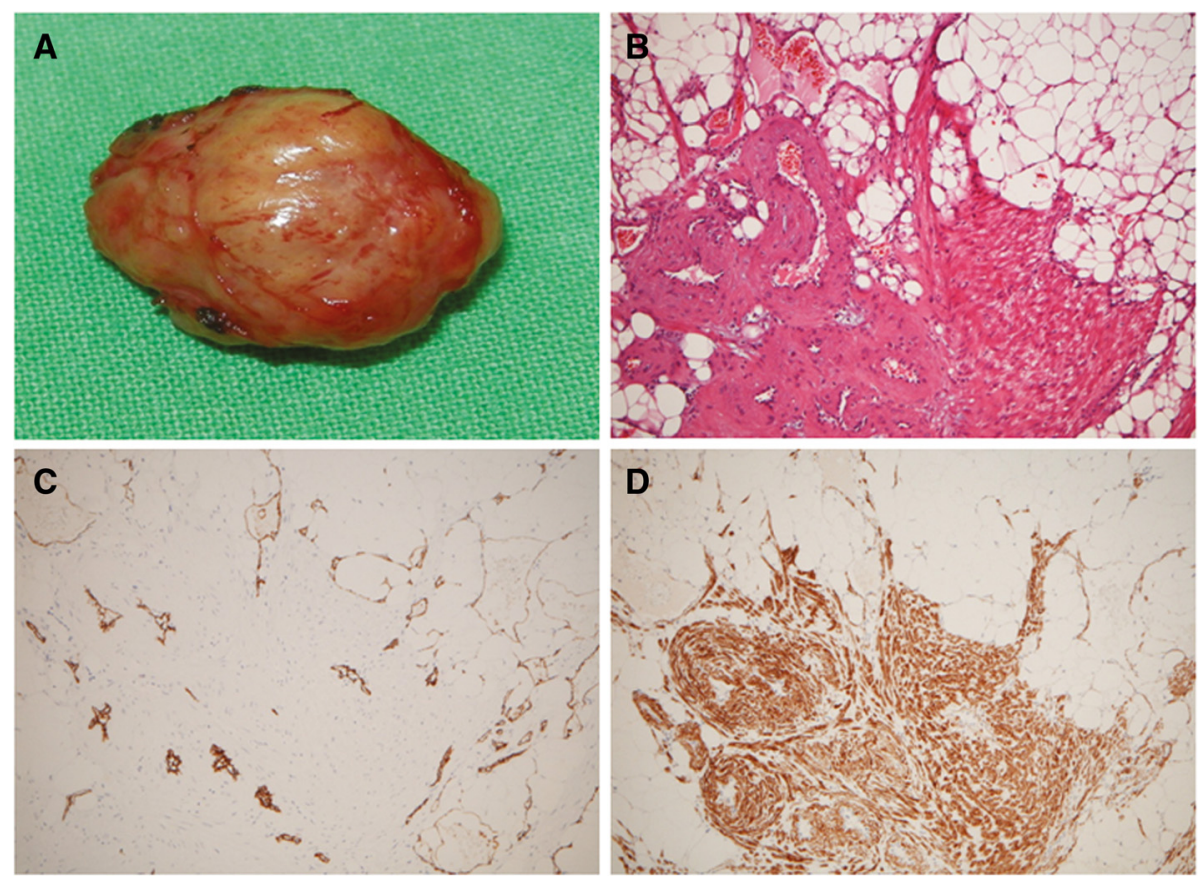

Fig. 2 Grossly, the tumor is a $1.8 \times 1.8 \times 1.3 \mathrm{~cm}$ yellowish, encapsulated, solid mass (a). Microscopic features of the tumor shows it is comprised of spindle to ovoid-shaped muscle cells interspersed with irregular vascular channels and mature adipocytes (b, hematoxylin and eosin stain, original magnification, $\times 100)$. Immunohistochemical staining reveals that the proliferating vessels are positive for CD34 (c) and smooth muscle cells are positive for HHF-35 (d) (original magnification, $\times 100$ )

are potentially malignancy. Therefore, wide excision and regular follow-up are warranted.

\section{Conclusion}

In summary, we report a case of primary orbital angiomyolipoma, which showed different immunohistochemical features from prior reported ocular PEComa. Although rare, angiomyolipoma should be added to the differential diagnosis of space-occupying orbital lesion.

\section{Consent}

Written informed consent was obtained from the patient for publication of this case report and any accompanying images. A copy of the written consent is available for review by the editor of this journal.

\section{Abbreviations}

PEComas: Perivascular epithelioid cell tumors; HHF35: Muscle actin antibody; HMB-45: Melanosome specific antigen; Melan-A: Melanoma antigen; $\mathrm{CT}$ : Computed tomography.

\section{Competing interests}

The authors declare that they have no competing interests.

\section{Authors' contributions}

CYL and HCK drafted this manuscript, collected the data, and reviewed the literature. WKY and SCK reviewed the literature. CCT interpreted the data, and critically reviewed the manuscript. CJLL critically reviewed the manuscript finally. All authors read and approved the final manuscript.

\section{Acknowledgement}

This study was partially supported by a grant (V104-C-092) from Taipei Veterans General Hospital, Taipei, Taiwan, and a grant (104-2314-B-075 -056 -MY2) from Ministry of Science and Technology, Taiwan.

\section{Author details}

${ }^{1}$ Department of Ophthalmology, Taipei Veterans General Hospital, No. 201, Sec.2, Shih-Pai Road, Taipei 11217Taiwan, R.O.C.. ${ }^{2}$ Department of

Ophthalmology, School of Medicine, National Yang-Ming University, Taipei,

Taiwan. ${ }^{3}$ Department of Ophthalmology, Koo Foundation Sun Yat-Sen

Cancer Center, Taipei 112, Taiwan.

Received: 6 February 2015 Accepted: 6 January 2016

Published online: 11 January 2016

\section{References}

1. Neumann HP, Schwarzkopf G, Henske EP. Renal angiomyolipomas, cyst, and cancer in tuberous sclerosis complex. Semin Pediatr Neurol. 1998;5:269-75.

2. Iyengar $\mathrm{P}$, Deangelis DD, Greenberg M, Taylor G. Perivascular epithelioid cell tumor of the orbit: a case report and review of the literature. Pediatr Dev Pathol. 2005;8:98-104.

3. Guthoff R, Guthoff T. Perivascular epithelioid cell tumor of the orbit. Arch Ophthalmol, 2008:126:1009-11.

4. Furusato E, Cameron JD, Newsom RW, Fujishiro T, Kojima T, Specht CS, et al. Ocular perivascular epithelioid cell tumor: report of 2 cases with distinct clinical presentations. Hum Pathol. 2010;41:768-72.

5. Schoolmeester JK, Howitt BE, Hirsch MS, Dal Cin P, Quade BJ, Nucci MR. Perivascular epithelioid cell neoplasm (PEComa) of the gynecologic tract: clinicopathologic and immunohistochemical characterization of 16 cases. Am J Surg Pathol. 2014;38:176-88.

6. Alvarez Alvarez C, Fernández Sanromán J, Fernández Castilla M, Badiola A. Sporadic oral angiomyolipoma. Case report. Med Oral Patol Oral Cir Bucal. 2007:12:E391-3.

7. Watanabe K, Suzuki T. Mucocutaneous angiomyolipoma. A report of 2 cases arising in the nasal cavity. Arch Pathol Lab Med. 1999;123:789-92. 
8. da Silva AA, Carlos R, Contreras E, de Almeida OP, Lopes MA, Vargas PA. Angiomyolipoma of the upper lip: case report and review of the literature. Med Oral Patol Oral Cir Bucal. 2007;12:E101-4.

9. Foschini MP, Corti B, DaCol M, Cenzi M, Zanella MD, Barbazza R. Angiomyolipoma of the parotid gland: a case report. Oral Surg Oral Med Oral Pathol Oral Radiol Endod. 1999:87:738-41.

10. Zoumalan Cl, Egbert PR, Warwar RE, McCulley TJ. Orbital giant cell angiofibroma recurring as a solitary fibrous tumor. Ophthal Plast Reconstr Surg. 2008;24:325-7.

Submit your next manuscript to BioMed Central and we will help you at every step:

- We accept pre-submission inquiries

- Our selector tool helps you to find the most relevant journal

- We provide round the clock customer support

- Convenient online submission

- Thorough peer review

- Inclusion in PubMed and all major indexing services

- Maximum visibility for your research

Submit your manuscript at www.biomedcentral.com/submit 